\title{
Optimization of Environmental Parameters for Short-term Storage of Big Onions and Evaluation of the Feasibility of Controlled Environmental Storage
}

\author{
R.S. Sabaragamuwa, D.A.N. Dharmasena ${ }^{1 *}$ and J. Mannaperuma ${ }^{2}$ \\ Postgraduate Institute of Agriculture \\ University of Peradeniya \\ Sri Lanka
}

\begin{abstract}
The annual requirement of big onion in Sri Lanka is around 200,000 Metric tonnes and only about $25 \%$ is locally produced at present. Seasonal cultivation during April to September is mainly limited to dry zone areas of the country. About 30-50\% postharvest losses are reported during short-term storage and sprouting and bulb rotting are the major causes of losses. Therefore, the objectives of this study were to study the present status of the onion postharvest handling, identify optimum storage conditions and analysis of the feasibility of providing those conditions for short-term storage. Primary and secondary data related to onion storage and marketing were gathered and analyzed to get information on postharvest handling, storage environment and marketing system. Storage behaviour of big onions under two temperatures: $25^{\circ} \mathrm{C}$ and $30^{\circ} \mathrm{C}$ and three $\mathrm{RH}$ conditions; $60 \%, 75 \%$ and 90\% was studied using a locally fabricated environment control chamber. A complete randomized design was used for the experiment. Loss of weight and external quality parameters were studied. The rainy season coincided with the storage period developing high $\mathrm{RH}$ above $75 \%$. Both the temperature and RH effects are significant at $\alpha=0.05$ on the percentage losses but there is no interaction effect between these two factors. The difference in the weight reduction due to loss of moisture was significant under two temperatures and three $R H$ conditions at $\alpha=0.05$. According to results $75 \% \mathrm{RH}$ and $25^{\circ} \mathrm{C}$ temperature were found to be the best condition for storage. According to energy requirement estimation, the environmental control during storage is feasible.
\end{abstract}

Key words: Bulb rotting, $R H$, Short-term storage, Temperature

\section{INTRODUCTION}

Big onion is an important condiment in daily Sri Lankan diet with a constant demand throughout the year totaling to an annual requirement of around 200,000 tonnes (Customs report, 2009). Its main appeal is due to the characteristic flavour and pungency caused by the volatile oil allyl-propyl-disulphide. National production of big onion was 52,918 tonnes in the year 2008 (Dept. Census and Statistics, 2009) which accounts for the 25\% of national requirement. The production is limited to a seasonal cultivation from April to September and harvested during September and October. Off-season shortage leads to import of big onions

To whom the correspondence should be addressed: dand@pdn.ac.lk

Department of Agricultural Engineering, Faculty of Agriculture, university of Peradeniya, Sri Lanka

Postgraduate Institute of Agriculture, University of Peradeniya, Peradeniya, Sri Lanka 
to meet the demand. The big onion imports during the year 2009 stood at 115,750 tonnes up to September, costing 3.24 billion rupees (Customs Report, 2009).

Optimum bulb formation of big onions depends on the photoperiod (long day conditions) and temperature (Brewster, 2008) and therefore, the cultivation is limited mainly to the Yala (dry) season under irrigation. Further, cultivation is also restricted mainly to few agroecological regions, especially DL1 due to other soil and environmental conditions (Dept. of Agriculture, 2006). One of the most important environmental conditions is the availability of ideal harvesting conditions in the growing area to minimize postharvest losses. The production is limited mainly to Yala season from late April to September depending on the rainfall pattern and long day conditions. Seed production takes place during both Maha and Yala seasons which is also a very profitable business as the seed prices are around Rs. 9,000$12,000 / \mathrm{kg}$. Around $7000 \mathrm{~kg}$ of seeds are produced altogether in both seasons which is less than half of the seed requirement of farmers in Dambulla. The rest of the seed requirement is met by importing Indian varieties. However, the germination percentage of the imported seeds is very poor and the demand and the purchasing price of bulbs are also lower than those of Sri Lankan varieties in the market. The major locally selected varieties grown in Dambulla area are Dambulla Red and Galewela Light Red, which were adopted from Pusa Red and Agri Found Light Red, respectively.

Big onion is a semi-perishable crop with high moisture content. The storability is relatively low with $30-50 \%$ postharvest losses are reported during short term storage under room conditions (Metthananda, 1992). This aggravates the problem of off-season shortage and reduces profits. In seed production also, the storage of bulbs for more than 6 months is needed but it leads to very high percentage ( $>50 \%)$ of losses (Metthananda, 1992; Personal communication with the Agricultural officers in Dambulla and CIC farm Pelwehera, 2009). Sprouting and bulb rotting are found to be the major causes of losses (Currah and Proctor, 1990). Bulb rotting has been identified as the major problem under warm, humid climatic conditions prevailing in Dambulla area in Sri Lanka.

Several methods, such as varietal selection, spacing and fertilizer management, pre-harvest fungicide application and field curing have been recommended to prevent the losses (Lesly, 2008). However, the loss is not yet properly addressed in Sri Lanka and remains as a major problem, may be due to practical limitations of those introduced techniques, cost factors and many other contributing factors at the field level.

Curing of big onions is one of the recommended practices for minimizing storage losses. This prevents the shrinkage during storage and minimizes the establishment of microorganisms that leads to rotting. In conventional field curing, the harvest is allowed to dry in natural convection of air at dry conditions for five to ten days depending on the climate till the neck seals and the outer protective cover is formed. It is also recommended to close the bulbs with onion leaves to prevent sun burn (Kader and Kitinoja, 1995). This method of field curing has limitations for many Sri Lankan farmers due to unexpected rains during harvesting time, damp conditions in paddy fields, lack of proper security and other socio-economic reasons. But if dry conditions prevail during the harvesting season, the bulbs cure well in the field and in the on-farm store especially in Dambulla or any dry zone area.

If the big onions harvested from late August to late September are stored for at least 3 months farmers could make maximum profits. In addition, it should be emphasized that the 
onion mother bulbs should be stored for about 8 months for Yala seed production. This long duration storage leads to a total loss of about $50 \%$.

The objectives of this study were to investigate the current production, postharvest handling and marketing system of big onions in Dambulla area, to study the storage behaviour of big onions under different controlled environmental conditions and to analyze the practical feasibility of controlled environment systems to minimize existing postharvest losses.

\section{METHODOLOGY}

\section{Current production, postharvest handling and marketing system}

Primary and secondary data were gathered and analyzed to get information on agricultural and cultivation practices, postharvest handling, storage practices and marketing system. Primary data were gathered through field visits and observations, for cultivation sites at Dambulla area and Dambulla Economic Center during the year 2009. Basic information was collected via interviews with respective officers, farmers and the officers at CIC Palwehera commercial farm. Secondary data was obtained mainly from annual reports and publications of Department of Agriculture, Department of Census and Statistics, Hector Kobbekaduwa Agrarian Research and Training Institute (HARTI) and Natural Resource Management Center (NRMC) of the Department of Agriculture.

Weather data (rainfall, temperature and $\mathrm{RH}$ ) of ten years and wholesale price data were analyzed for the optimization of storage conditions and to determine the storage duration for getting the price advantage.

\section{Storage behaviour of big onions under different environmental conditions}

After analyzing 10 years of weekly weather data in Dambulla area (weekly mean rainfall, mean maximum and minimum air temperature and mean $\mathrm{RH}$ at Mahailuppallama weather station), two temperatures and three RH conditions were selected for the study of storage beaviour.

Samples were collected from two cultivation sites at Dambulla in May 2010. The bulbs were obtained with leaves and trimmed in the laboratory. This was an off-season onion crop and therefore the bulbs were not in optimum average size as those of September harvest (onion harvest season). The bulbs were also cured under ambient environmental conditions in a farmer storage house. At the time of sampling, unexpected poor environmental conditions prevailed with heavy rains and high $\mathrm{RH}$.

Two temperature $\left(25^{\circ} \mathrm{C}\right.$ and $\left.30^{\circ} \mathrm{C}\right)$ were selected with three constant $\mathrm{RH}$ conditions $(60 \%$, $75 \%$ and $90 \%$ ). A complete randomized design with 6 replicates for each treatment was used. One replicate contained around $250 \mathrm{~g}$ of onions with average size of $45 \mathrm{~mm}$ diameter/bulb.

During storage, the temperature was controlled over time using an electronic circuit (Fig. 1). 


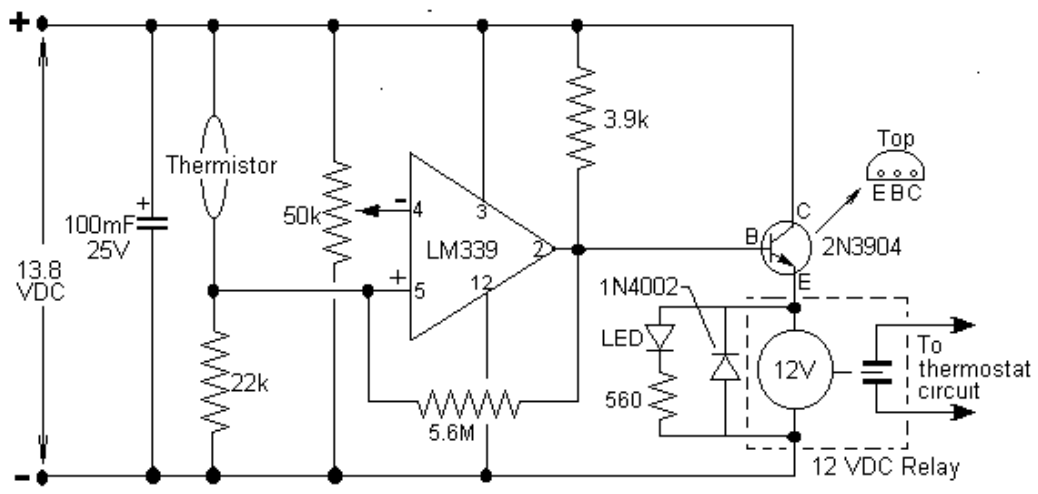

Fig. 1. Circuit diagram of the temperature controller

To maintain the temperature, pre-heated air was circulated inside 6 insulated chambers at $25^{\circ} \mathrm{Cand} 30^{\circ} \mathrm{C}$ temperatures, in which six samples per each chamber with different $\mathrm{RH}$ conditions were arranged. Airtight containers were used to store the onion samples. Containers had to be opened at $48 \mathrm{~h}$ intervals to allow fresh air supply to maintain natural respiration and to prevent physiological disorders. This time interval was calculated according to the respiration rate which was determined by the rate of carbon dioxide production as $27-29 \mathrm{mg} / \mathrm{kg} / \mathrm{h}$ at $25-27^{\circ} \mathrm{C}$ (Hardenberg et al., 1986).

Thermistors were used to sense the temperature in each block. The incoming hot air flow to the chambers were independently controlled using the electronic circuit. The controlled environmental chambers were kept in a cold room in which the temperature was nearly between $21-23^{\circ} \mathrm{C} \pm 0.05$. RH was controlled using saturated salts of $\mathrm{NaBr}, \mathrm{NaCl}$ and $\mathrm{KNO}_{3}$ at $60 \%, 75 \%$ and $90 \%$, respectively (Rockland, 1960).

Percentage loss of onions due to rotting and sprouting with time were recorded for one and half month storage period. Rotten bulbs due to neck rot and sprouted bulbs were observed and removed at two day intervals throughout this storage period and percentage loss was calculated as a percentage of initial total number.

Weight loss of onion bulbs with storage time was recorded at one week intervals. A moisture removal curve was plotted and weight loss due to drying throughout the storage period was calculated under three RH and two temperature conditions. For this purpose, weights of individually labeled onion bulbs were recorded. Quality of onions was also observed for scale development, scale colour, surface fungal growth, root and shoot growth. Observations were made once in two days for onion external quality parameters.

Data analysis was done by two-way Analysis of Variance statistical technique, using SAS (2.1 release) software. Experiment was considered as a two factor factorial design. Hence the effects of two major factors, $\mathrm{RH}$ and temperature as well as the presence of any interaction effect were also studied. 


\section{Feasibility of a commercial storage facility with controlled environment system to}

A commercial storage facility can be developed to maintain the best storage conditions determined under laboratory conditions. It will incorporate temperature and/or humidity control depending on the findings of the laboratory study.

Internal and external temperature and $\mathrm{RH}$ at an onion storage house in Dambulla area were recorded for 3 months at 10 min intervals during harvesting and storage period in the year 2009 to obtain the applicable external conditions for the commercial storage design.

A data logger (CR 10) was used to record weather data. Wet bulb and dry bulb temperatures were recorded and following equations were used to calculate $\mathrm{RH}$.

$$
W=[(T c-T w b)(C p)-L v(E s w b / P)] /[-(T c-T w b)(C p v)-L v]
$$

where; $W=$ actual mixing ratio of air, $C p=$ specific heat of dry air $(\mathrm{J} / \mathrm{g}), C p v=$ specific heat of water vapour at constant pressure $(\mathrm{J} / \mathrm{g}), L v=$ latent heat of vaporization $(\mathrm{J} / \mathrm{g}), T c=$ air temperature in ${ }^{\circ} \mathrm{C}, T w b=$ wet bulb temperature in ${ }^{\circ} \mathrm{C}, E s w b=$ saturation vapour pressure at the wet bulb temperature $(\mathrm{mb})$ and $P=$ atmospheric pressure $(\mathrm{mb})$ at surface.

$W_{s}=E s w b / P$

$W S=$ saturation mixing ratio

$R H \%=\left(\frac{w}{W s} * 100\right)$

According to the dry bulb temperature and calculated RH values, the absolute humidity was calculated using psychrometric calculations. These values were used to calculate moisture loads from the external environment as explained by Harriman (1990).

Product moisture removal at recorded drying rate of onion bulbs under optimum RH and temperature conditions, respiration weight loss, moisture load due to permeation via walls of the store house and human activities were considered in moisture load estimation. Energy need for cooling was also estimated using average ambient environmental temperature during storage period. Cooling load and moisture load were estimated for an existing ten tonne store with dimensions of $4 \mathrm{~m}$ width, $5 \mathrm{~m}$ length and $5 \mathrm{~m}$ height.

\section{RESULTS AND DISCUSSION}

\section{Effects of climatic conditions on storage}

Analysis of mean monthly rainfall data for last ten years (1999-2009) showed that the rainy season coincides with the storage period (September- December) causing postharvest losses during storage (Fig. 2). Problems encountered during handling the harvest in the fields, high $\mathrm{RH}$ conditions, spread of diseases and unavailability of sufficient storage facilities further aggravates the losses. 


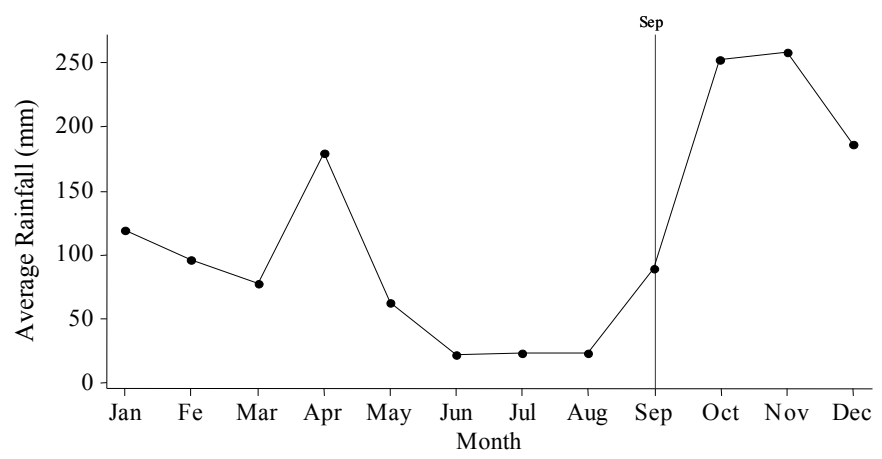

Fig. 2. Mean monthly rainfall at Dambulla (NRMC of the Dept. of Agriculture, 1999-2009)

Mean maximum and minimum temperature records show that the maximum temperature ranges from $29-33^{\circ} \mathrm{C}$ while the minimum temperature range from $21-24^{\circ} \mathrm{C}$ during this period (Fig. 3).

According to $\mathrm{RH}$ data records, the maximum $\mathrm{RH}$ occurs during early October to early January period (Fig. 4) and the day time RH values remain close to $90 \%$ which is a high value and the minimum $\mathrm{RH}$ during this period was always greater than $75 \%$.

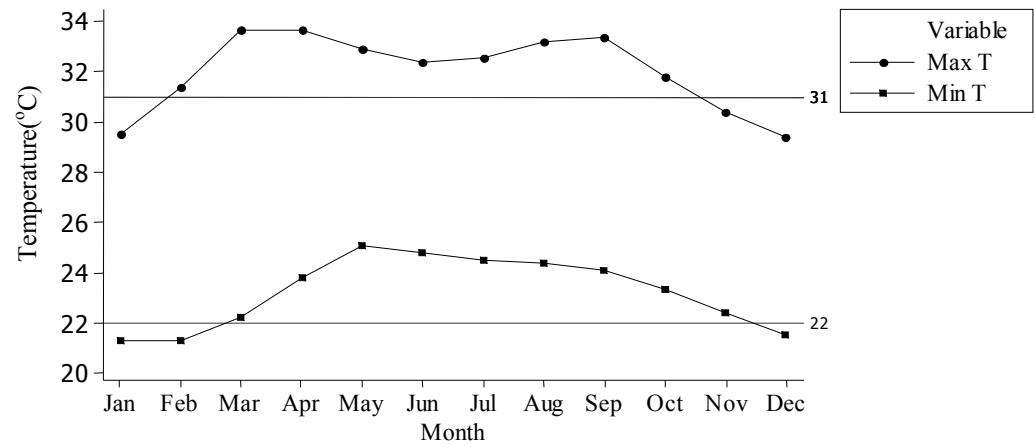

Fig. 3. Mean monthly maximum and minimum temperatures (NRMC of the Dept. of

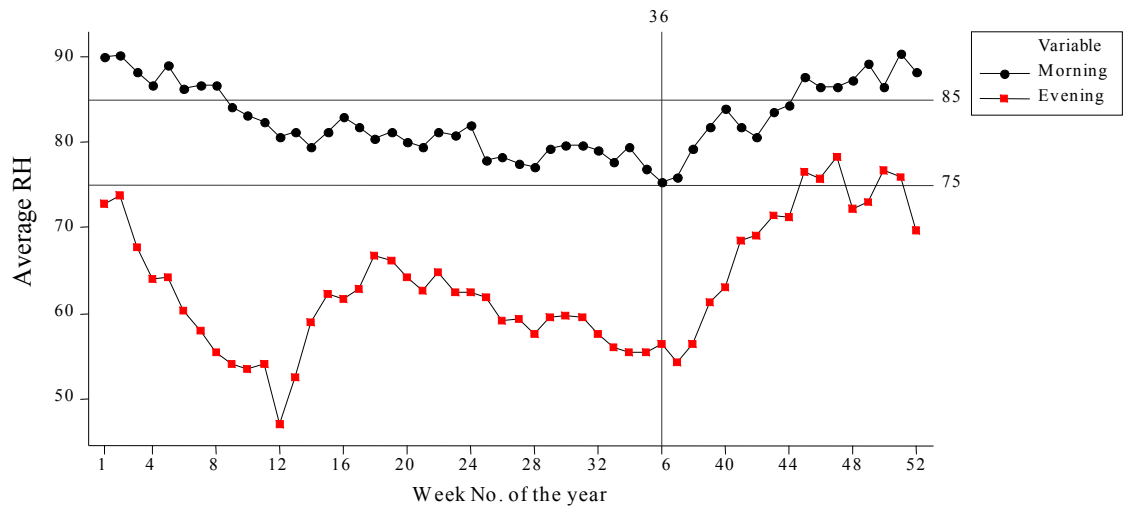

Fig. 4. Average weekly RH values recorded at 8.00 a.m and 3.00 p.m. (NRMC, Dept. of Agriculture, 1999-2009). 
Although the night time temperatures are relatively low, the $\mathrm{RH}$ goes up. Therefore, dehumidification during night time is important for minimizing the loss.

\section{Analysis of price data}

The trend of wholesale onion purchasing price data from 1999-2009 at the Dambulla Economic Center revealed that the prices of big onion fall during September - October period and it rises to the highest during November to December period (Fig. 5). This fluctuation is artificially created due to the change of import tax of onions during the harvesting time by the government.

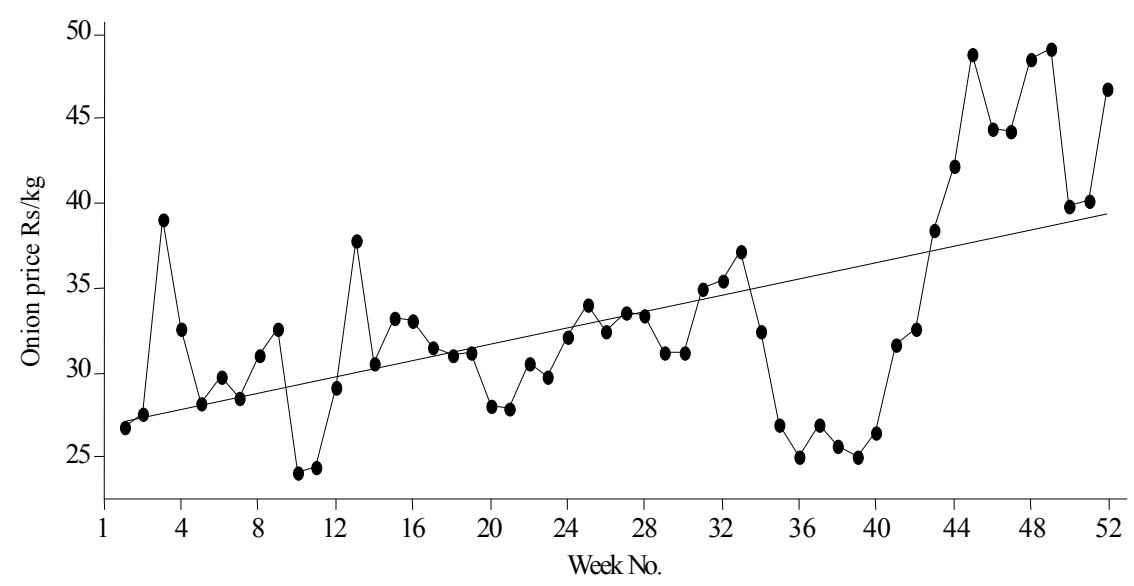

Fig. 5. Wholesale onion prices at Dambulla Economic Centre (Market information from HARTI, 2009)

\section{Storage behaviour of big onions under different controlled environment conditions}

Since this experiment was planned for short-term storage conditions, data collected during first one and half months was analyzed and discussed in this paper. After keeping onion samples for 5 weeks under six temperature and humidity combinations, data were obtained to study the storage behaviour.

\section{Percentage loss due to rotting and sprouting}

The results were compared by two way analysis of variance statistical technique using SAS (2.1 release) software. Major effects due to temperature and RH as well as effect of interaction were considered at $95 \%$ confidence interval. $\mathrm{P}$ values associated with temperature (T) and relative humidity (RH) were 0.0395 and 0.0004 , respectively (Table 1 ). Thus it could be concluded that the effects of different temperature and RH levels tested are significantly different. Mean separation procedure showed that the losses at RH levels $60 \%$ and $75 \%$ are not significantly different, but $90 \% \mathrm{RH}$ level contributes to a higher loss.

According to results, storage behaviour under two temperature levels was significantly different. The loss percentage at $25^{\circ} \mathrm{C}$ was lower than $30^{\circ} \mathrm{C}$ storage temperature. This may be basically due to the reduction of the rate of metabolic activities and other processes due to 
lower temperature (Kader, 2002). The $\mathrm{P}$ value associated with interaction effect is 0.72 , which indicated no effect of interaction (Fig. 6).

Table 1. Analysis of variance for loss percentage

\begin{tabular}{lccccc}
\hline Source & DF & ANOVA SS & Mean Square & F Value & P value \\
\hline Temperature & 1 & 355.55 & 355.55 & 5.33 & 0.0395 \\
RH & 2 & 2177.77 & 1088.88 & 16.33 & 0.0004 \\
T*RH & 2 & 44.44 & 22.22 & 0.33 & 0.7230 \\
\hline
\end{tabular}

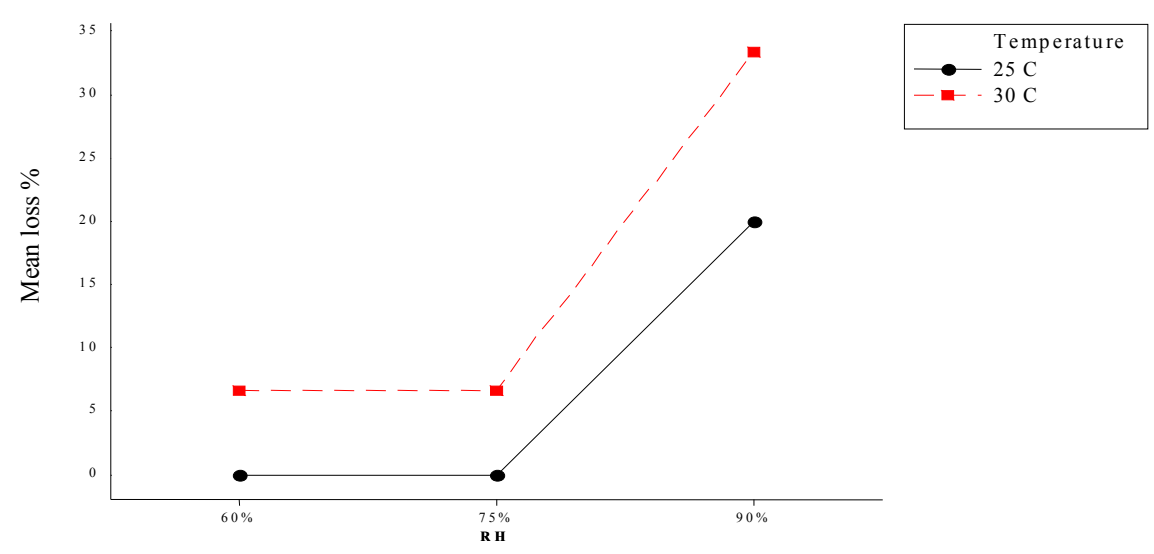

Fig. 6. Interaction plot of temperature and RH (data means) for percentage loss

\section{Quality observations}

Onion bulbs stored at $90 \% \mathrm{RH}$ condition were of inferior quality than those stored at $60 \%$ and $75 \% \mathrm{RH}$ in terms of root and shoot growth, surface fungal growth and outer cover and colour development. Good scale development with rustling noise could be observed of bulbs stored at $60 \%$ and $75 \% \mathrm{RH}$ conditions nearly 2-3 weeks after storage. Good colour development of outer skin was evident in onion bulbs stored at $60 \% \mathrm{RH}$, and $25^{\circ} \mathrm{C}$. It could be observed that shoot and root growth was initiated rapidly at $90 \% \mathrm{RH}$.

\section{Loss of fresh weight due to moisture loss}

Mean values for percentage weight loss for moisture loss were $7.4 \%, 6.5 \%$ and $4.4 \%$ at $60 \%$, $75 \%$ and $90 \% \mathrm{RH}$ levels, respectively. Statistical analysis revealed that differences in moisture removal is significantly different at $90 \% \mathrm{RH}$ level while the other two levels showed no significant difference.

The difference in the weight reduction due to moisture loss was significant under two temperature conditions at 0.05 level of $\alpha$. As shown in Table 2, P values associated with effect of RH levels and temperature levels were 0.002 and 0.032 , respectively while the $\mathrm{P}$ value for interaction effect was 0.67 , thus showing no effect of interaction between major factors. 
The moisture loss is significantly low at $25^{\circ} \mathrm{C}$ and $90 \% \mathrm{RH}$ as shown in Fig. 7.

Table 2. Analysis of Variance for moisture loss

\begin{tabular}{lccccc}
\hline Source & DF & ANOVA SS & Mean square & F Value & P value \\
\hline Temperature & 1 & 10.33 & 10.33 & 5.82 & 0.0328 \\
$\mathrm{RH}$ & 2 & 37.66 & 18.83 & 10.60 & 0.0022 \\
$\mathrm{~T} * \mathrm{RH}$ & 2 & 1.43 & 0.715 & 0.40 & 0.6773 \\
\hline
\end{tabular}

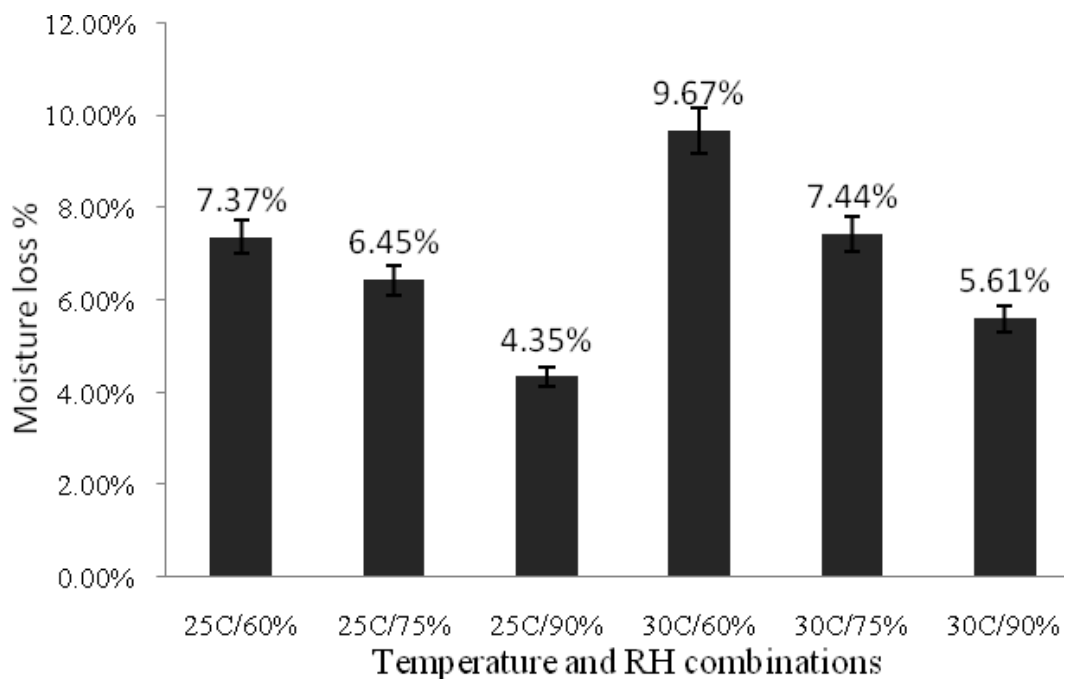

Fig. 7. Percentage reduction of weight due to moisture loss during storage of onion at different temperatures and RH after 6 weeks of storage.

Further reduction of temperature will further reduce the loss and minimize the microbial growth leading to rotting of bulbs. However, $25^{\circ} \mathrm{C}$ and $30^{\circ} \mathrm{C}$ were selected to minimize the energy requirement.

\section{Calculation of energy needs of the prospective design}

As the first step, dry bulb and wet bulb temperatures recorded using the data logger were compiled and the corresponding RH values were calculated by equations 1,2 and 3 using Microsoft Excel software.

\section{Prevailing exterior conditions using psychrometric equations}

The following values were obtained for the environmental parameters used in energy and moisture load calculations.

Average RH over storage period $=82.3 \%$

Average dry bulb temperature $=27.4^{\circ} \mathrm{C}$

Absolute humidity $=0.02293 \mathrm{~kg} / \mathrm{kg}$ of dry air 


\section{Conditions to be maintained inside the storage house}

RH over storage period $=75 \%$

Average dry bulb temperature $=25^{\circ} \mathrm{C}$

Absolute humidity $=0.01798 \mathrm{~kg} / \mathrm{kg}$ of dry air

\section{Moisture load estimation}

In moisture load calculations, the dimensions of a 10 tonne storage house, with $4 \mathrm{~m}$ width, 5 $\mathrm{m}$ height and $5 \mathrm{~m}$ length, which has been already built in Dambulla area were considered.

Total moisture load was estimated as $0.7134 \mathrm{~L} / \mathrm{h}$. To remove this much of moisture, the approximate power requirement is $500 \mathrm{~W}$.

\section{Cooling load estimation}

In maintenance of suggested temperature under prevailing exterior conditions, the calculated heat load is approximately $800 \mathrm{~W}$. Total energy need could be achieved by operating an air conditioner with the capacity of $1.5 \mathrm{~kW}$.

Considering approximate operating hours, the running cost of this type of air conditioner is around Rs. 24,000.00, for the whole storage period. Considering the trend of big onion price fluctuations over the storage period, it can be predicted that this technology will be economically and practically feasible as the farmer is capable of getting at least Rs. 40,000.00 additional profit.

\section{CONCLUSIONS}

According to the results of the investigation, it can be concluded that coincidence of rainy weather resulting in high RH leads to high postharvest losses of big onions by neck rotting and sprouting. Results of the study of controlled environmental conditions revealed that the best $\mathrm{RH}$ and temperature combinations associated with minimum loss percentage are $60 \%$, $75 \% \mathrm{RH}$ at $25^{\circ} \mathrm{C}$. Considering the minimum operating cost, $75 \% \mathrm{RH}$ and $25^{\circ} \mathrm{C}$ conditions could be selected as optimum parameters for storage of big onions under local conditions. Energy need and cost estimations for operating a 10 tonne farmer storage house under these controlled environmental parameters, shows that this system would be technically and economically feasible for short-term storage of big onions for local farmers.

\section{ACKNOWLEDGEMENTS}

The authors are grateful to Mr. P.R.P.Y. Pallemulla, Deputy Director of Agriculture, Matale and Agricultural instructors at Dambulla, Mr. W.M.R.G.K. Wijethunge and Mr. W. A. M. S. P Abesekara for providing necessary information and samples. Officers at CIC, Palwehara Farm are also acknowledged. Authors also thank Technical Mr. K.G.W.U. Karunasinghe for his invaluable support in instrumentation and Mr. P.V.B.L. Wickramasinghe for fabricating controlled environment chambers. 


\section{REFERENCES}

Brewster, J. (2008). Onion and other vegetable alliums. $2^{\text {nd }}$ Ed. Crop Production Science in Horticulture Series. 15. CAB International, Wallingford, UK. pp127.

Census and Statistics reports (2009). Department of Census and Statistics, Sri Lanka.

Currah, L. and Proctor, F.J. (1990). Onion in tropical regions. Bulletin no.35, National Resource Institute, Chatham, Kent, UK. pp.79.

Customs Report (2009). Sri Lanka Customs, Sri Lanka.

Department of Agriculture. (2006) [on line]. [Accessed on 01.09.2008]. Available at http://www.agridept.gov.lk/ agelinks.php?pagelink $=$ Big\%20 onion \%20\& heading $=$ Condiments

Hardenberg, R.E., Watada, A. E. and Wang C. Y. (1986).The commercial storage of Fruits, Vegetables and Florist and Nursery stocks, Agriculture Handbook Number 66, USDA. pp.12.

Harriman, L. G. (1990). Moisture load calculations. Chapter 5. pp. 1-19. In: Harriman, L. G. (Ed). Handbook of Dehumidification. Munters Cargocaire, MA, USA.

Kader, A.A. and Kitinoja, L. (1995). Cyber extension: FAO Corporate Document Repository: Small scale postharvest handling practices manual [on line]. [Accessed on 10.08.2009]. Available athttp://www.fao.org/ Wairdocs/ X5403E/ x5403e04.htm

Kader, A. A. (2002). Postharvest Biology and Technology: An Overview. Chapter 4. pp 3947. In: Kader, A. A. (Ed), Postharvest Technology of Horticultural Crops. University of California, Agriculture and Natural Resources, Publication 3311.

Lesly, W.D. (2008). Cyber extension: Agronomic Research on Big Onion [on line]. [Accessed on 14.09.2009]. Available at http://www.goviya.lk/ agri_learning/ Loku_ loonu/ research/Shashya_vidyathmaka/p20.pdf

Metthananda, K.A. (1992). Varietal evaluation of storability of big onions. Seasonal Reports, Maha 1991/92, Agriculture Research Station, Mahailuppallama.

Rockland, L.B. (1960). Saturated Salt Solutions for Static Control of Relative Humidity between $5^{\circ}$ and $40^{\circ} \mathrm{C}$, Analytical Chemistry 32, 1375 . 